\title{
The Effectiveness of using SMS Instalment Alert Platform on Customer Satisfaction in the Retail Clothing Stores in Zimbabwe
}

\author{
Douglas Chiguvi ${ }^{1 *}$, Collen Mahambo ${ }^{1}$, Keofe Tender Kgetho ${ }^{1}$
}

${ }^{1}$ BA ISAGO University, BOTSWANA

*Corresponding Author: dchiguvi@gmail.com

Citation: Chiguvi, D., Mahambo, C. and Kgetho, K. T. (2020). The Effectiveness of using SMS Instalment Alert Platform on Customer Satisfaction in the Retail Clothing Stores in Zimbabwe. Dutch Journal of Finance and Management, 4(2), em0066. https://doi.org/10.29333/djfm/9300

\section{ARTICLE INFO}

Received: 15 Jul. 2020

Accepted: 25 Sep. 2020

\begin{abstract}
The study was focusing on the effectiveness of using (SMS) instalment platform as a way of meeting customer satisfaction at Edgars stores Ltd in Zimbabwe. The main objective of the research was to measure the effectiveness of SMS installment platform on customer satisfaction. Causal research design was employed and a simple random sampling technique was used in selecting the respondents. Questionnaires were used to gather data from a sample size of 357 consisting of 342 customers and 15 staff members of Edgars' stores Ltd. The data collected was analyzed through the use of SPSS version 20 in order to determine the strength of the relationship and the moderating effect. The data findings were presented in form of tables. The research findings from the hypothesis tests explored that there is a strong significant and positive relationship between SMS installment platform service and customer satisfaction. The study recommended the company to use SMS platform for other promotion activities like sending bonus vouchers, news release and advertisements. This will encourage more customers to shop hence improved market share. The SMS platform can also be used to give after sales services and other personalized information and birthday wishes. All these will increase customer satisfaction.
\end{abstract}

Keywords: Short Message Services (SMS) installment platform, customer satisfaction

\section{INTRODUCTION}

Edgars Stores Limited is a limited company incorporated and domiciled in Zimbabwe whose shares are publicly traded. Its core business is the retailing of clothing, footwear, textiles and accessories. The company aims at supplying its customers with value for money by providing quality merchandise for the family at competitive prices. It has as well devised a method of alerting customers on the due installment every month. SMS has evolved into one of the most successful wireless data services in recent years and had proven to be one of the best after-sale services activities (Yang, 2005). The short message services (SMS) method is an improvement to the archaic and out dated instalment by post statement which were to a great extent a disadvantage to the store in terms of the late payments. Customers complained bitterly of the late arrival of the statement therefore, failing to do payments in time. This was seen as burdensome to the company which incurred losses through late payment of instalments. Edgar's store is one of the Zimbabwe's market leaders in this field and the company resolves to remain so. However, the challenge is that the company is losing market share due to stiff competition from upmarket boutiques which are mushrooming everywhere in Zimbabwe. Other competitors like Topics, Jet are increasing pressure by bringing in new better products. Competition is also coming from informal sectors dealers who sell secondhand clothes at lower prices. This has also increased the competition in the industry. The number of active accounts has dropped to low levels by 109186 from 203728 that is 46.41\% between 2014 and 2015 (The Edgars Club Magazine, 2016). To withstand this pressure the company has intensified its efforts on customer retention through customer satisfaction. The best strategy to intensify is to fully adopt an aggressive and efficient, time saving and error free SMS platform for installment alert. Today market is a more customer oriented in the sense that all the business operations revolve around satisfying the customer by meeting their needs through effective service. After sales service plays an important role in customer satisfaction. After-sale service is important because it helps to ensure that customers are satisfied with their purchases and in case of any difficulty installing or setting up equipment, they can receive help. More so, after-sales service is commonly acknowledged as a potential source of revenue, profit and competitive advantage in most manufacturing industries.

After-sales services such as the short message service (SMS) instalment platform can create sustainable relationships with customers and contribute significantly to customer satisfaction. Short Message Service (SMS) is the 


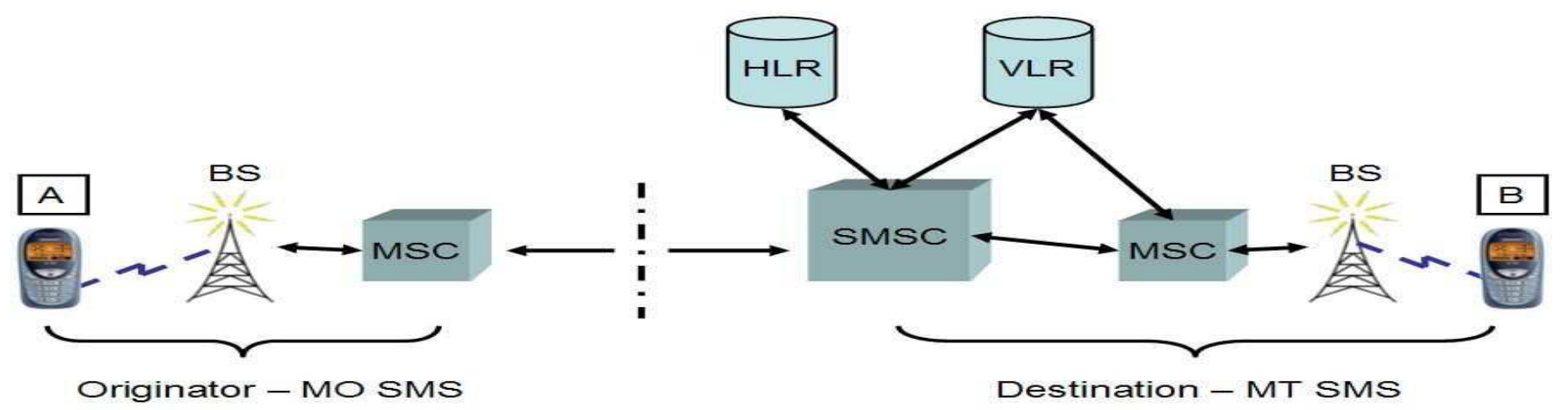

Figure 1. Typical handset-to-handset network architecture for SMS Source: Adopted from Zerfos et al. (2005)

transmission of short text messages to and from a mobile phone, fax machine, and/or IP address. Messages must be no longer than 160 alphanumeric characters and contain no images or graphics. SMS is a relatively simple messaging system provided by the mobile phone networks. In today's competitive world, differentiation is a significant factor in the success of the service provider. SMS provides a powerful vehicle for service differentiation. If the market allows for it, SMS can also represent an additional source of revenue for the service provider. SMS provides guaranteed message delivery and at the same time delivering of messages to multiple customers at a time. This saves time and money hence high profits to the company. By offering different after-sales services during the various stages of the primary product lifecycle, the provider can ensure product functionality and thereby customer satisfaction. This may lead to a fruitful relationship between the provider and the customer over time, allowing for more transactions. Retaining customers are the most profitable ones as they require less marketing effort and relationship building. Therefore, after-sales services have acquired a critical role as a means to satisfy and retain customers. Especially in a time when firms are experiencing increased pressure to downsize operations and to become more highly specialized in their core competencies, they demand more tailored services.

\section{LITERATURE REVIEW}

\section{Short Messaging Service (SMS)}

Text messaging, or texting, is the act of typing and sending a brief, electronic message between two or more mobile phones or fixed or portable devices over a phone network. The term originally referred to messages sent using the Short Message Service (SMS), has grown to include messages containing image, video, and sound content known as MMS messages. The sender of a text message is known as a texter, while the service itself has different colloquialisms depending on the region. It may simply be referred to as a text in North America, the United Kingdom, Australia and the Philippines including Zimbabwe, an SMS in most of mainland Europe, and a TMS or SMS in the Middle East and Asia (Ellison and Winther, 2007). In current cellular networks, SMS messages are transmitted over the Common Channel Signaling System 7 (SS7), which is the digital signaling control network used by network elements of wire line and wireless telephone carriers to exchange control information for call setup, routing, mobility management (Day, 2005).

Figure 1 shows the typical network elements and architecture employed for handset-to-handset communication (Point-to-Point SMS). Conceptually, the network architecture is split into two segments that are central to the SMS philosophy of operations. The elements at the sender, that is the Mobile Originating (MO) part, include the Mobile Station (MS) of the sender, the Base Station (BS) that provides the radio infrastructure for wireless communications, and the Originating Mobile Switching Center (MSC) that manages route sand switches all traffic into and out of the cellular system on behalf of the mobile device of the sender (Zerfos et al., 2005). The elements at the destination of the message, more often known as the Mobile Terminating (MT) part, also feature a base station and an MSC (Terminating MSC) for the receiver. In addition, an SMS Center (SMSC) acts as a centralized, store and forward server that is responsible for accepting, storing, retrieving subscriber information, and forwarding messages to the intended recipients of the messages. It is assisted by two databases, namely the Home Location Register (HLR) and the Visitor Location Register (VLR), in which location information is kept regarding the subscribers and their mobile devices (such as the address of the MSC that the device is associated with). For more details on the SMS network architecture and its operations, as well as other scenarios with fixed entities that are capable of sending and receiving short messages (e.g., application servers) (Campbell, 2005).

\section{Benefits of SMS Platform}

According to Cheng et al., (2009), SMS messages are an alternative to voice communication over the telephone when silent, private, or very brief communications are best and since they are somewhat non-traditional. SMS messages have an element of playfulness that often encourages creativity, and customers can find such novelty addictive. SMS messages can be sent between users or to and from an application, which gives service development an extra flexibility that encourages innovation (Carter et al., 2004). SMS works as a payment reminder which is immediate, intimate but non-intrusive and it has unbeatable cut through. Compared to other forms of communication, SMS is both less expensive and more effective. Traditional mail is slow, expensive, and inevitably 


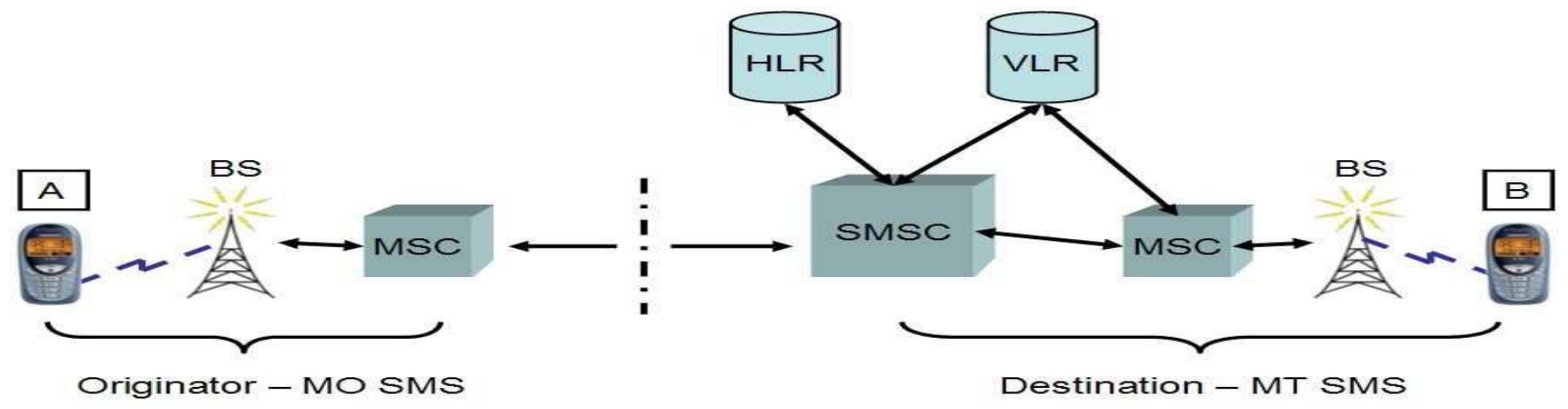

Figure 2. Disconfirmation theory

Source: Adopted from Szymanski et al. (2000)

gets lost amidst a pile of junk mail (Haghiria, 2010). Email can be inexpensive but response rates are typically less than $1 \%$ compared to SMS. Human phone calls can be effective but are also extremely expensive. Moreover, as customers increasingly screen calls, human phone calls are losing their effectiveness (Fill, 2005). According to Haghiria (2010), 97\% of text messages are opened and read within three minutes. Moreover, with a software-based SMS platform, Edgars Accounts Receivable team can reach overdue customers with little or no staff time required. Payment reminders and overdue notices can be sent with the click of a button or even automated. Customers prefer receiving a message note than having to make phone calls. In addition SMS provides a powerful vehicle for service differentiation. Edgar's stores can customize services for each individual through the use of SMS platform which will give them a competitive advantage. If the market allows for it, SMS can also represent an additional source of revenue for the service provider. The benefits of SMS to service provider like Edgars include convenience, flexibility, and seamless integration of messaging services and data access. From this perspective, the primary benefit is the ability to use the handset as an extension of the computer. SMS also eliminates the need for separate devices for messaging because services can be integrated into a single wireless device- the mobile terminal. Cheng et al., (2009) argued that it is too fast communication service and it delivers with in a very short time. Cheng et al., (2009) explains some of the benefits of SMS as a marketing communication tool as: high speed text message delivery and also promote interactivity. More customers reach (Mass communication) and response rate for SMS is five times more than direct postal mail. Dickinger et al., (2004) argued that SMS marketing is very much cost effective and the only cost which company has to bear is the cost of purchasing phone numbers; however this cost seems very minor after the SMS reaches to its exact target customer. Furthermore, Mallat (2007) argued that mobile phone technology is developing very rapidly and this led to increase in the number of mobile users. This is an opportunity for marketers like Edgars Stores to use this channel effectively for communication. According to Fill (2005) the retail industry can get benefits from this SMS service as it is same as e-mail and likewise sales promotion and brand awareness can be created by using mobile marketing. Furthermore, mobile coupons for price discount can be sent through SMS for generating sales promotion (Carter, 2004). Text messages can be used to interact with automated systems, for example, to order products or services, or participate in competition. All of these benefits are attainable quickly, with modest incremental cost and short payback periods, which make SMS an attractive investment for service providers.

\section{Relationship between SMS Installment Service and Customer Satisfaction}

Businesses need to attract and establish a customer market and would need to retain it through satisfaction. That is the key to its business performance (Johnson et al., 2001). In order to attain this goal, a company should have a high satisfaction rate from its clients. The increasing competition is forcing the business sectors to pay much and more attention to satisfying customers. Colgate (1990) suggests that increased levels of customer satisfaction is frequently attributed or linked to positive outcomes for a firm. Measurement of the rate of customer satisfaction is also a measurement of how products and services supplied by a company meet or surpass customer expectation. According to Oliver (1999) satisfied customer is a key factor in the formation of a customer's desire to purchase future products. Nowadays, customer satisfaction is considered as the corporate level strategy and it is a source of successful entrepreneurship. Henkel (2006) found that customers who are satisfied with service intent to increase the usage and purchase in future times. According to Parasuraman, Zeithmal and Berry (1988) customer satisfaction is the outcome of service quality. The relationship between service quality and customer satisfaction is supported in disconfirmation theory explained below.

\section{Disconfirmation Theory}

Szymanski et al. (2000: 9), in disconfirmation theory argue that satisfaction is related to the size and direction of the disconfirmation experience that occurs as a result of comparing service performance against expectations. Szymanski et al. (2000: 9) state that, the disconfirmation paradigm is the best predictor of customer satisfaction. According to Szymanski et al. (2000), satisfaction is the customer's fulfillment response and it is a judgment that a product or service feature or the product or service itself provides a pleasurable level of consumption related fulfillment including levels of under or over fulfillment. 
Table 1. Demographic profiles of respondents

\begin{tabular}{|c|c|c|c|c|c|c|c|}
\hline \multicolumn{4}{|c|}{ EMPLOYEES RESPONDENTS } & \multicolumn{4}{|c|}{ CUSTOMERS RESPONDENTS } \\
\hline \multicolumn{2}{|l|}{ Category } & \multirow{2}{*}{$\begin{array}{c}\text { Number } \\
4\end{array}$} & \multirow{2}{*}{$\begin{array}{c}\% \\
26.7\end{array}$} & \multicolumn{2}{|c|}{ Category } & \multirow{2}{*}{$\begin{array}{c}\text { Number } \\
150\end{array}$} & \multirow{2}{*}{$\begin{array}{c}\% \\
44\end{array}$} \\
\hline Gender & Male & & & Gender & Male & & \\
\hline & Female & 11 & 73.3 & & Females & 192 & 56 \\
\hline & Totals & 15 & 100 & & Totals & 342 & 100 \\
\hline \multirow[t]{5}{*}{ Age } & $20-30 y r$ & 11 & 73.3 & Age & 20-30yrs & 96 & 28 \\
\hline & 31-40yrs & 2 & 13.3 & & $31-50 y r s$ & 178 & 52 \\
\hline & 41-50yrs & 1 & 6.7 & & $51-60 y r s$ & 68 & 20 \\
\hline & 50 above & 1 & 6.7 & & 60above & - & - \\
\hline & Totals & 15 & 100 & & & & \\
\hline
\end{tabular}

Source: primary data

\section{Empirical Evidence}

Collins (2014) examined Short Messaging Service (SMS) as a marketing communication tool and customer satisfaction in India banking sectors. One hundred and three (103) customers participated in the study through random selection. A Likert scale questionnaire was used to gather responses from the customers. The study found that there is relationship between SMS and customer understanding of customer care and customer satisfaction. The study found out that there is a relationship between Short Message Service (SMS) and customer satisfaction in the banking industry. Another study by Esmaeilpour (2014), carried out a study on the relationship between SMS instalment service and customer satisfaction in retailing sector in Iran. A sampling size of 400 questionnaires was equally distributed by using systematic sampling in each of the four retailing companies that were chosen at random resulting in 100 respondents per chosen stratum. The researcher observed that SMS instalment service enhances customer satisfaction. Peersman, and Cvetkovic, (2003) took tests to determine whether there is a relationship between SMS instalment platform and customer satisfaction relationship in banking industry in London. A sampling size of 350 questionnaires was equally distributed by using stratified random sampling in each of the 3 telecom companies which were chosen at random, resulting in 90 respondents per chosen stratum. Out of the 350 questionnaires that were sent out, 175 were completed and returned, recorded a response rate of $49.14 \%$. Finally, they concluded that there is a positive relationship between SMS instalments service platform and customer satisfaction. In another research conducted by Goffin (2005), on retailing industries in New Zealand, the major concern of that study was to examine the relationship between SMS platform and customer satisfaction. The findings from that study suggest that there is a relationship between SMS platform and customer satisfaction relationship.

\section{RESEARCH METHODOLOGY}

Causal research design was employed. The aim was to determine the effect of the independent variable (SMS) has on the dependent variable (customer satisfaction). The targeted populations of the study are the customers of Edgars Stores Ltd who are account holders and have been active for past the five years (2011-2016). The researcher used probability sampling method of simple random sampling method. Questionnaires were used to collect the data. To measure SMS platform service the researcher adopted skepticism toward advertising scale by
Obermiller and Spangenberg (1998). The scale consist of nine items using a scale which stretches from $1=$ strongly disagree to 5 =strongly agree. The scale was tested for validity and reliability. Coefficient alpha estimates of internal reliability consistency for the first and second administration were 0.85 and 0.86 respectively. Carl (1998) tested the reliability of the measurement instrument and found to be highly reliable and valid with cronbach's alpha $=0.827, \mathrm{AVE}=0.605$ and construct reliability $=0.844$. To measure customer satisfaction, the researcher used five point likert scale by Smith et al., (1964) which stretches from $1=$ strongly disagree to $5=$ strongly agree. The Cronbach alpha was 0.83 and the standard loadings constitute the AVE values which range from 0.610 to 0.835 for all the variables. The variance deviation $\mathrm{R}$ square was 0.544 . The instrument proves the existence of both discriminant validity and convergent validity. Westblook (2010) tested the reliability of the measurement instrument and found to be highly reliable and valid with cronbach's alpha $=0.829$, $\mathrm{AVE}=0.605$ and construct reliability $=0.843$. The researcher used Statistical Package for Social Sciences (SPSS) software to analyze the data obtained from the questionnaire. The SPSS software helped the researcher to use regression statistical to estimate the relationships between the SMS platform instalment service and customer satisfaction. The data was presented in form of tables for easy understanding.

\section{DATA FINDINGS}

\section{Demographic Profile of Respondents and Response Rate}

The results of the demographic profile from Table 1 shows that $73.3 \%$ of Edgars stores employees are female and male are $26.7 \%$. Women have got higher percentage than men because women do more shopping of clothes than men. The table also shows the age of employees in which $73.3 \%$ consist of employees aged $20-30,31-40$ years have $13.3 \%$, $41-50$ years occupy $6.7 \%$ whilst the employees who are 50 years and above has $6.7 \%$. In Table 1 there are results for customers who visit Edgar's stores were $56 \%$ were female and $44 \%$ were male. According to the result from Table 1, it shows that customers with the age group between $31-50$ years has a $52 \%$ of the total population visiting Edgars stores followed by $20 \%$ of the customers aged between 51-60 years, then 28\% of the customers are aged between $20-30$ years and lastly those aged 61 and above constitutes $0 \%$. 
Table 2. Regression coefficient of SMS instalment service on customer satisfaction Coefficients

\begin{tabular}{|c|c|c|c|c|c|c|}
\hline & \multirow{2}{*}{ Model } & \multicolumn{2}{|c|}{ Unstandardized Coefficients } & \multirow{2}{*}{$\begin{array}{c}\text { Standardized Coefficients } \\
\text { Beta }\end{array}$} & \multirow{2}{*}{$\mathbf{T}$} & \multirow{2}{*}{ Sig. } \\
\hline & & B & Std. Error & & & \\
\hline \multirow{2}{*}{1} & (Constant) & .475 & .092 & & 5.192 & .000 \\
\hline & SMS instalment service & .649 & .038 & .761 & 17.223 & .005 \\
\hline
\end{tabular}

a. dependent Variable: customer satisfaction

Table 3. The model summary of SMS instalment platform effectiveness and customer satisfaction

\begin{tabular}{ccccc}
\hline Model & R & R Square & Adjusted R Square & Std. Error of the Estimate \\
\hline 1 & $.728^{\mathrm{a}}$ & .530 & .528 & 1.120
\end{tabular}

a. Predictors: (Constant), customer satisfaction

\section{Relationship between SMS Platform Services and Customer Satisfaction}

In this study, the researcher analyzed the effectiveness of using (SMS) Edgar's instalment platform as a way of meeting customer satisfaction. $\mathrm{H} 1$ : there is positive relationship between SMS instalment platform effectiveness and customer satisfaction. The results of the hypothesis from the regression analysis are shown by Table 2 .

Table 2 shows the results of SMS instalment servicecustomer satisfaction relationship. From Table 2, it is clearly shown that there was positive SMS instalment servicecustomer satisfaction relationship as evidenced by a standardized regression coefficient value of .761, significant value of .005 and the $t$ value of 5.192. This means that a positive change or an increase in the level of SMS instalment service causes an increase in customer satisfaction and a decrease in SMS instalment service also causes customer dissatisfaction. Since the results proved that there was a positive SMS instalment service-customer satisfaction relationship, therefore the hypothesis of the study was fully accepted.

The model summary shows that the R square is 0.530 which implies that $53 \%$ of the changes in customer satisfaction were resultant from a change in SMS instalment platform service and the other $47 \%$ changes might be caused by other factors.

\section{DISCUSSION}

The purpose of the current study was to investigate the causal relationship between (SMS) Edgars instalment platform and customer satisfaction. The main emphasis of the study was to prove that there is significant and positive relationship between SMS installment platform service and customer satisfaction. This study fully accepted the hypothesis $\left(\mathrm{H}_{1}\right)$ of the study which states that that there is positive relationship between SMS instalment service and customer satisfaction since the results shown that change in R square is $53 \%$ (see Table 3) and statistically significant as shown by $p=0.005$ (see Table 2). This hypothesis was also supported in the research carried out by Collins (2014) who took a study to determine whether there is relationship between SMS and customer understanding of customer care and customer satisfaction in India banking sector. It was also confirmed and supported in disconfirmation theory by Szymanski et al., (2000). This study has increased the body of literature by bringing up a study in the African context specifically in Zimbabwe which was not included in the body of literatures. Moreover, the results from this study will provides encouraging empirical support both for theory development as well as for hypothesized the effectiveness of using (SMS) Edgars instalment platform and customer satisfaction relationship. Furthermore, these results will help the marketing managers to assess importance of communication and the marketing mix in order to implement micromarketing strategies so as to enhance competitive advantage in the clothing retail sector in Zimbabwe which will result in high market share. In short, these results will enable the marketing managers of Edgars stores Ltd to properly make use of the SOSTAC model propounded by Smith (1993) which is a marketing plan guideline. Thus, the managers will be able to analyze the results which leads them to have marketing objectives, knowing how exactly they can strategies (thus, how do they achieve their smart goals), they should know the tactical action for example, the way they might use the communication tools, they may also know the action plans required (thus, who is going to do what?) and finally the management will know how to control performance for the betterment of the organization.

\section{CONCLUSION AND RECOMMENDATIONS}

This research was directed to investigate the effectiveness of using (SMS) Edgar's instalment platform as a way of meeting customer satisfaction. The causal research design was used in this study to unveil what (SMS) Edgars instalment platform effectiveness causes on customer satisfaction. The research findings pointed out that (SMS) Edgars instalment platform service is an important asset of the business operations and it must be handled carefully so that the company can be successful. The study revealed that (SMS) Edgars SMS instalment platform is the major determinant of customer satisfaction in the clothing retail industry and has a greater influence on customer satisfaction. Basing on the above conclusion it is recommended that the top management of Edgars stores Ltd should also do promotions through this platform as a way of increasing its market share. Mobile coupons for price discount can be sent through SMS for generating sales promotion. This will encourage customers to buy more clothes and as result this improves the market share of the company hence more profits to the company. Furthermore, Edgars is recommended to personalize messages because this is crucial in forming and strengthening the bonds of loyalty between consumers and the company which result in high levels of customer satisfaction. For example sending birth 
day wishes to its customers. Edgars needs to possess comprehensive databases that contain relevant information about their target customers. When consumers receive only relevant SMS that speak to their interests, they will be more likely to read future ads from the same source which in turn increases customer satisfaction. The company is also recommended to seriously consider the entertainment aspect of SMS platform by adding games, jokes, graphics, or catchy and memorable jingles to their SMS platform service. This will make the consumer feel they are interacting with a fun diversion. And the consumer will be more likely to forward the message to friends, to save it on their phone and show friends, or to pass along the joke. All of this positive word of mouth can have a potent positive effect on consumer satisfaction and market share.

\section{REFERENCES}

Campbell, B., Mahy, R. and Jennings, C. (2006). The message session relay protocol. In Work in Progress. https://doi.org/10.17487/rfc4975

Carter, L. and Belanger, F. (2004, January). Citizen adoption of electronic government initiatives. In System Sciences, 2004. Proceedings of the 37th Annual Hawaii International Conference on (pp. 10-pp). IEEE. https://doi.org/10.1109/HICSS.2004.1265306

Cheng, J. M. S., Blankson, C., Wang, E. S. T. and Chen, L. S. L. (2009). Consumer attitudes and interactive digital advertising. International Journal of Advertising, 28(3), 501525. https://doi.org/10.2501/S0265048709200710

Colgate, M. (1997). Personal bankers and relationship marketing: a New Zealand case study. Journal of Financial services marketing, 2, 84-96.

Collins, K. K. (2014). SMS and Customer Satisfaction in the Banking Industry.

Day, J. Rosenberg, and H. Sugano. A model for presence and instant messaging. IETF Request For Comments (RFC 2778), February 2000. https://doi.org/10.17487/rfc2778

Dickinger, A., Haghirian, P., Murphy, J. and Scharl, A. (2004, January). An investigation and conceptual model of SMS marketing. In System sciences, 2004. proceedings of the 37th annual hawaii international conference on (pp. 10-pp). IEEE. https://doi.org/10.1109/HICSS.2004.1265096

Ellison, S and Winther, M., (2007). Analysts, “Common Short Codes: The Time Is Now For Mobile Marketing and Outreach," IDC.
Esmaeilpour, M. (2014). Analyzing after Sales Services in House Appliances Products and Measuring Customers Satisfaction: A Survey in Bushehr, Iran. International Journal of Marketing and Management, 2(1), 62-79.

Fill, C. (2005). Marketing Communications: Engagements Strategies and Practice (4th ed.). Pearson Education Ltd.

Goffin, K. (1999). Customer support: a cross-industry study of distribution channels and strategies. International Journal of Physical Distribution \& Logistics Management, 29(6), 374398. https://doi.org/10.1108/09600039910283604

Haghirian, P., Madlberger, M. \& Inoue, A. (2008). Mobile advertising in different stages of development: a crosscountry comparison of consumer attitudes. In Hawaii International Conference on System Sciences, Proceedings of the 41st Annual (pp. 48-48). IEEE. https://doi.org/10.1109/HICSS.2008.318

Johnson, M. D., Gustafsson, A., Andreassen, T. W., Lervik, L.\& Cha, J. (2001). The evolution and future of national customer satisfaction index models. Journal of economic Psychology, 22(2), 217-245. https://doi.org/10.1016/S01674870(01)00030-7

Mallat, N. (2007). Exploring consumer adoption of mobile payments-A qualitative study. The Journal of Strategic Information Systems, 16(4), 413-432. https://doi.org/10.1016/j.jsis.2007.08.001

Obermiller, C. \& Spangenberg, E. R. (1998). Development of a scale to measure consumer skepticism toward advertising. Journal of consumer psychology, 7(2), 159-186. https://doi.org/10.1207/s15327663jcp0702_03

Oliver, R. L. (1999). Whence consumer loyalty?. The Journal of Marketing, 33-44.

Parasuraman, A., Zeithaml, V. A. and Berry, L. L. (1985). A conceptual model of service quality and its implications for future research. the Journal of Marketing, 41-50.

Peersman, C., Cvetkovic, S., Griffiths, P. and Spear, H. (2000). The global system for mobile communications short message service. IEEE Personal Communications, 7(3), 1523. https://doi.org/10.1109/98.847919

Szymanski, D. M. and Hise, R. T. (2000). E-satisfaction: an initial examination. Journal of retailing, 76(3), 309-322. https://doi.org/10.1016/S0022-4359(00)00035-X

Zerfos, P., Meng, X., Wong, S. H., Samanta, V. and Lu, S. (2006, October). A study of the short message service of a nationwide cellular network. In Proceedings of the 6th ACM SIGCOMM conference on Internet measurement (pp. 263268). ACM. https://doi.org/10.1145/1177080.1177114 